\title{
MORFOLOGIA URBANA DAS ÁREAS DE FUNDO DE VALE DO CÓRREGO ÁGUA BÔSCOLI EM PRESIDENTE PRUDENTE, SP
}

\author{
Aline Passos Scatalon, Arlete Maria Francisco
}

Universidade Estadual Paulista - UNESP - Campus de Presidente Prudente. Departamento de Planejamento, Urbanismo e Ambiente. Arquitetura e Urbanismo. Processo FAPESP № 2012/17506-1

\section{RESUMO}

Os rios e córregos sempre foram vistos como obstáculos para o desenvolvimento urbano e, raramente, como elementos paisagísticos incorporados ao desenho da cidade. São comuns ocupações irregulares das suas margens, na Área de Preservação Permanente (APP), o que gera alterações no ciclo hidrológico, e contribui para o processo de degradação dos corpos d'água. Portanto, nesta pesquisa se propõe realizar o levantamento morfológico das áreas de fundo de vale urbanizadas do Córrego Água Bôscoli em Presidente Prudente, com o objetivo de identificar os tipos de tecidos urbanos, verificando a forma de ocupação das Áreas de Preservação Permanente. $O$ trabalho é justificado pela contribuição à discussão do modelo de ocupação dessas áreas em cidades brasileiras e do seu planejamento, bem como de alternativas para futuras intervenções em áreas não ocupadas, a partir do estudo sobre o crescimento da cidade, do seu traçado e parcelamento, da tipologia das edificações e articulações entre estes.

Palavras-chave: Morfologia urbana, Fundos de Vale, Áreas de Preservação Permanente, Córrego Água Bôscoli, Presidente Prudente-SP.

\section{INTRODUÇÃO}

A realidade das margens de corpos d'água das cidades brasileiras é, na maioria dos casos, de degradação, em consequência da ocupação irregular de habitações, de ruas e avenidas ou de outros elementos urbanos que impermeabilizam as terras adjacentes, ocasionando prejuízos à própria população e ao meio ambiente.

Culturalmente, a população se serve das águas dos rios e córregos, interferem no seu curso e o polui, sem a devida consciência da importância da sua preservação e conservação. Isso vem se modificando nas ultima décadas, mas a passos bem lentos. A superação do modelo de produção e apropriação das áreas de fundo de vales, fundamentado em relações conflituosas entre o homem e a natureza e no desprezo às características específicas do sítio urbano, se coloca como um desafio ao planejamento urbano, o que pode ter uma boa perspectiva em cidades médias como Presidente Prudente, onde tais áreas não estão totalmente ocupadas.

É importante romper o paradigma de que os cursos d'água são problemas para as cidades e verificar as suas potencialidades. Faz-se necessária uma mudança de atitude com relação à conformação da cidade, tanto no desenho urbano das áreas de expansão quanto no redesenho 
dos espaços consolidados. Os cursos d'água são elementos fundamentais de inserção da natureza nas cidades e é um determinante do desenho urbano, quando não são mascarados ou descaracterizados pelo homem.

A análise morfológica é fundamental para o conhecimento das formas tradicionais de ocupação das áreas adjacentes aos cursos d'água da cidade. Assim, o objetivo deste trabalho é identificar os diversos tipos de tecidos urbanos existentes nas áreas de fundo de vale do Córrego Água Bôscoli em Presidente Prudente - SP, verificando a forma de ocupação territorial das suas Áreas de Preservação Permanente. Neste contexto, propõe-se realizar o levantamento morfológico destas áreas, a fim de discutir seu modelo de ocupação. Ressalta-se que esta pesquisa é apoiada pela Fapesp e encontra-se em desenvolvimento.

\section{METODOLOGIA}

Para a realização da pesquisa, foi utilizada a metodologia de análise urbana proposta por LAMAS (1993), DEL RIO (1990), e PANERAI (1999). Assim, identificaram-se os seguintes temas para o estudo da morfologia urbana: história, crescimento, forma, entrevistas e levantamento fotográfico e iconográfico.

Os aspectos gerais dos tecidos urbanos podem ser divididos em três tipos de malhas urbanas fechadas ${ }^{1}$ : malha urbana fechada ortogonal, malha urbana não ortogonal, e malha urbana irregular (MASCARÓ, 2003).

A partir destas definições referentes ao traçado, foram elaboradas fichas de análise, uma para cada bairro, a fim de identificar os tipos de tecidos urbanos existentes nos loteamentos adjacentes ao córrego, de modo de que fosse possível fazer uma comparação entre eles. Estas fichas de análise apresentam as datas de implantação, sua localização em relação ao córrego, traçado, a tipologia de lotes, e uma consideração final dessas características. Um modelo desta ficha é mostrado na Figura 1.

\footnotetext{
${ }^{1}$ Já que não encontramos malhas abertas na área de estudo, do entorno Córrego Água Bôscoli.
} 


\section{FICHA 1}

\section{Bairro: VILA BOSCOLI}

Dados: - Ano de planta: 1964

- Num. de quadras do loteamento: 27 quadras.

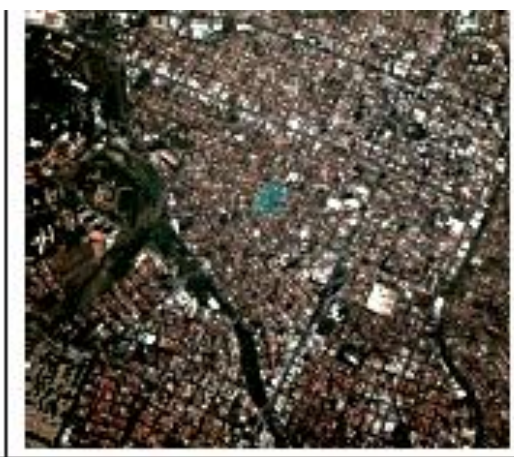

Traçado:

$\infty$

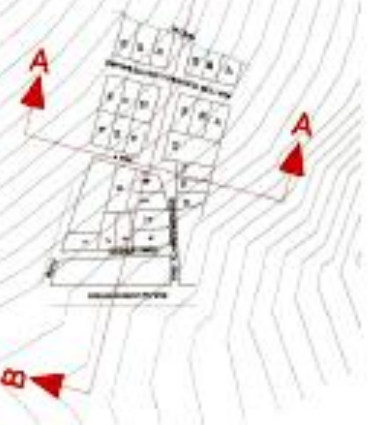

Quadras e Lotes:

\section{LOTES}
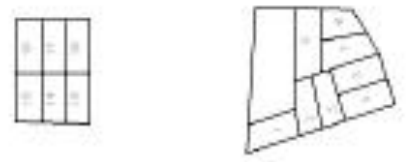

Retangular

\section{Cortes:}

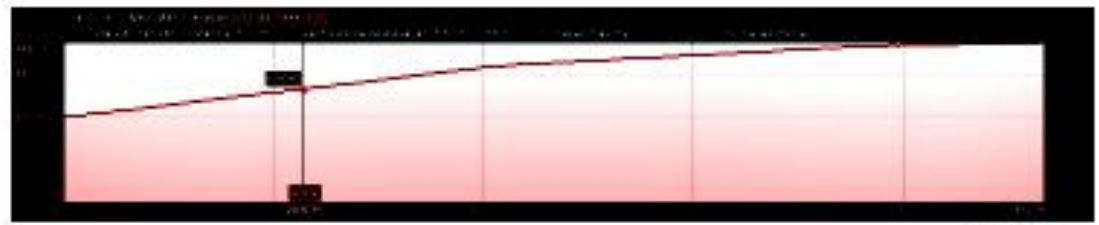

Corte A-A

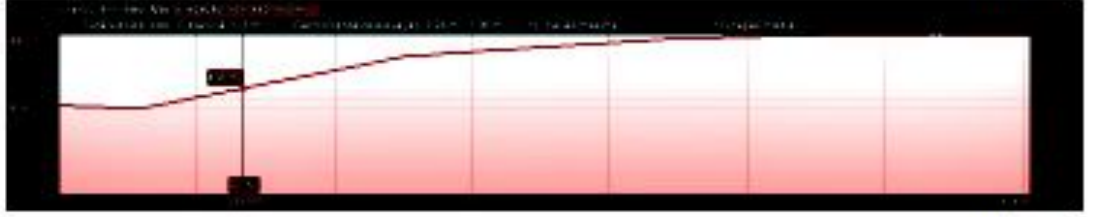

Corte B-B

\section{Obserraçòes:}

- Traçado irregular (quebra com o sentido dos loteamentos iniciais);

- Apenas uma quadra é ortogonal (retangular), e todas as demais têm forma irregular. A presença do córrego não influencia no planejamento do traçado, que as quadras lotes têm seus fundos voltados diretamente para ele (o córrego como fundo de lote).

- As ruas não apresentam grandes problemas quanto à declividade, já a maior inclinação é próxima de $8 \%$ (dentro do percentual da NBR - 15\%).

Figura 1. Ficha modelo de análise de traçado dos loteamentos - Vila Bôscoli. 


\section{RESULTADOS}

A ocupação da área do córrego em estudo iniciou-se por volta da década de 40, quando a cidade começava a crescer, tendo como orientação as áreas compreendidas pelos interflúvios entre os Córregos Bacarin e Água Bôscoli e entre este e o Córrego do Veado (SPOSITO, 1995, p. 09). Até o final da década de 1970, toda a área já estava ocupada. É possível entender como se deu essa ocupação em direção ao córrego, por meio da Figura 2, que mostra a evolução dos loteamentos adjacentes ao longo dos anos.

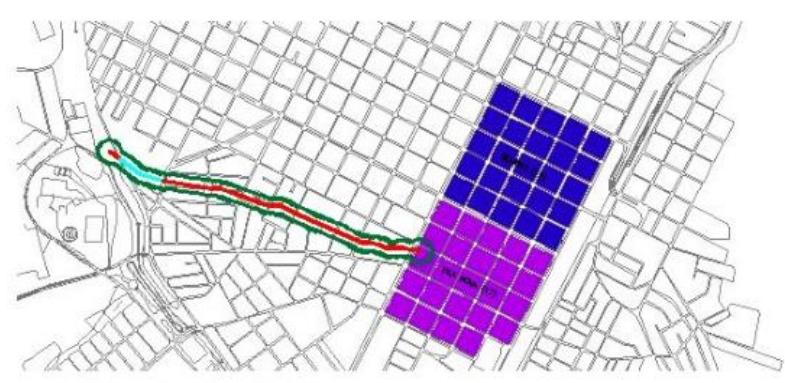

Até a decada de 20

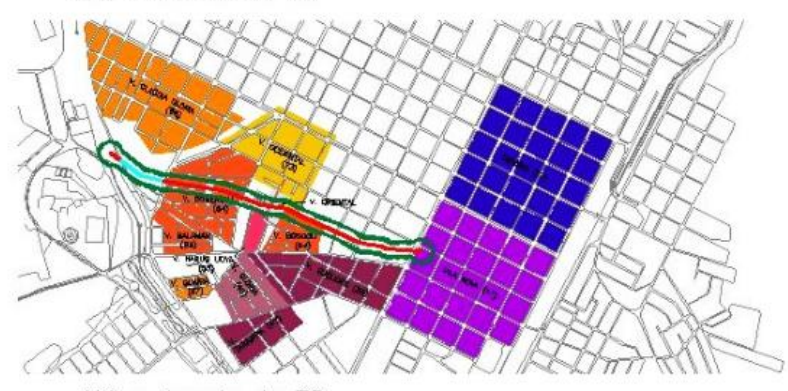

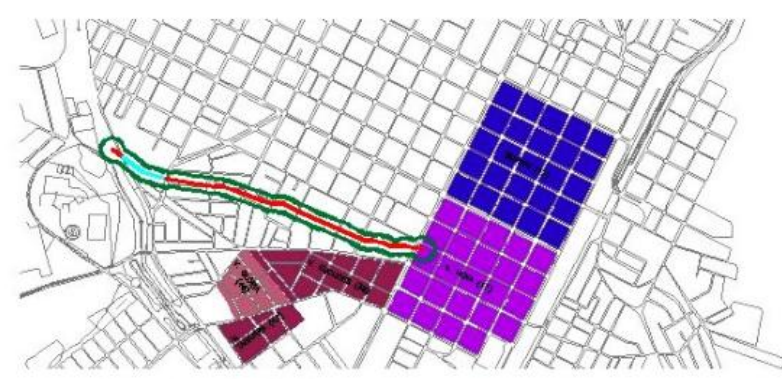

Até a decada de 40

Figura 2. Mapa da evolução da área de entorno do Córrego Água Bôscoli. Fonte: SPOSITO (1983) e acervo da Prefeitura de Presidente Prudente.

Conforme foi sendo ocupada a área do entorno do córrego, o traçado foi deixando de ser ortogonal (forma dos loteamentos que deram origem à cidade). O primeiro loteamento de Presidente Prudente, a Vila Goulart, possuía uma regularidade de planta, que se repetiu na Vila Marcondes - regularidade típica da época dos arruamentos projetados pelos agrimensores (PEREIRA, 2000).

Os loteamentos do entorno do córrego apresentam nova tipologia de traçado e de orientação. Isso se dá, provavelmente, devido à necessidade de adequação do relevo, mais acentuado em razão ao córrego, e também por causa da própria interferência do corpo d'água como elemento físico, quando as edificações não ocupam a sua superfície. 
É suposto que essa mudança de traçado não tenha acontecido devido ao tempo, por uma possível evolução do desenho urbano, pois loteamentos de ocupação posteriores aos do entorno do córrego voltam a possuir esta característica de traçado, com os lotes quadrados - como é o caso da Vila Cláudia Glória e Vila Comercial (Figura 3).

Por meio das fichas elaboradas para análise do traçado dos loteamentos e uma comparação entre elas, percebeu-se que há uma propensão para quadras quadradas. Alguns loteamentos apresentam quadras de formato quadrado em seu interior, e então próximo às bordas, devido ao próprio formato irregular do loteamento, há a necessidade de quadras também irregulares, resultando em um traçado misto - ortogonal e não ortogonal (Figura 3). O formato dos loteamentos deixa de ser quadrado (como eram os primeiros), e adquire formas irregulares, o que também contribui para a existência dessa adaptação de traçado. $O$ traçado ortogonal permanece, mesmo de forma mista.

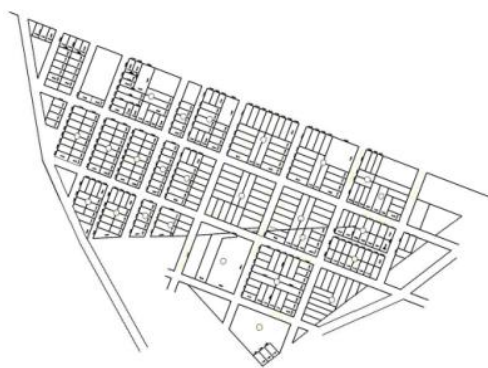

Vila Cláudia Glória

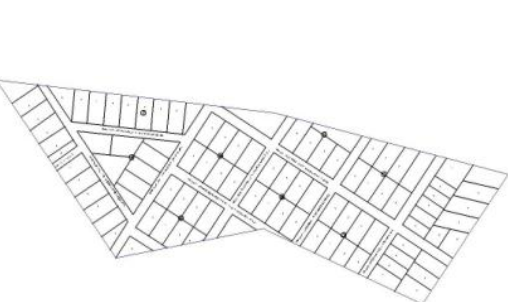

Vila Euclides

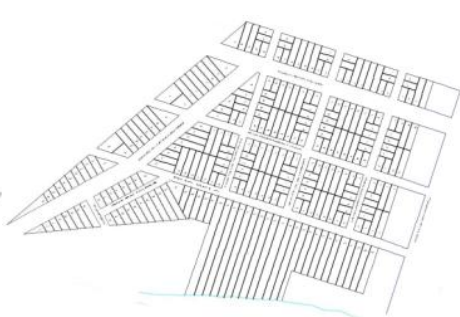

Vila Ocidental

Figura 3. Loteamentos de traçado misto. Fonte: Prefeitura de Presidente Prudente.

A reurbanização do córrego aconteceu na década de 70, por meio de recursos provenientes do programa do governo federal denominado "Comunidade Urbana para Recuperação Acelerada" (CURA I). O CURA do Governo Federal consistiu em um Programa de Complementação Urbana criado em 1973 pelo Conselho de Administração do Banco Nacional da Habitação (BNH) para complementação de infraestrutura urbana em áreas consolidadas, a fim de promover o adensamento populacional e combater os vazios urbanos especulativos. Ele era destinado a cidades com mais de 50 mil habitantes, consideradas de porte médio, como era o caso de Presidente Prudente. Neste caso, o CURA I foi implantado no período entre 19767 e 1982 com obras destinadas à porção oeste da cidade (FRACISCO, 2012). Na ocasião, o córrego foi canalizado e tamponado em quase toda a sua extensão (Figura 4). 


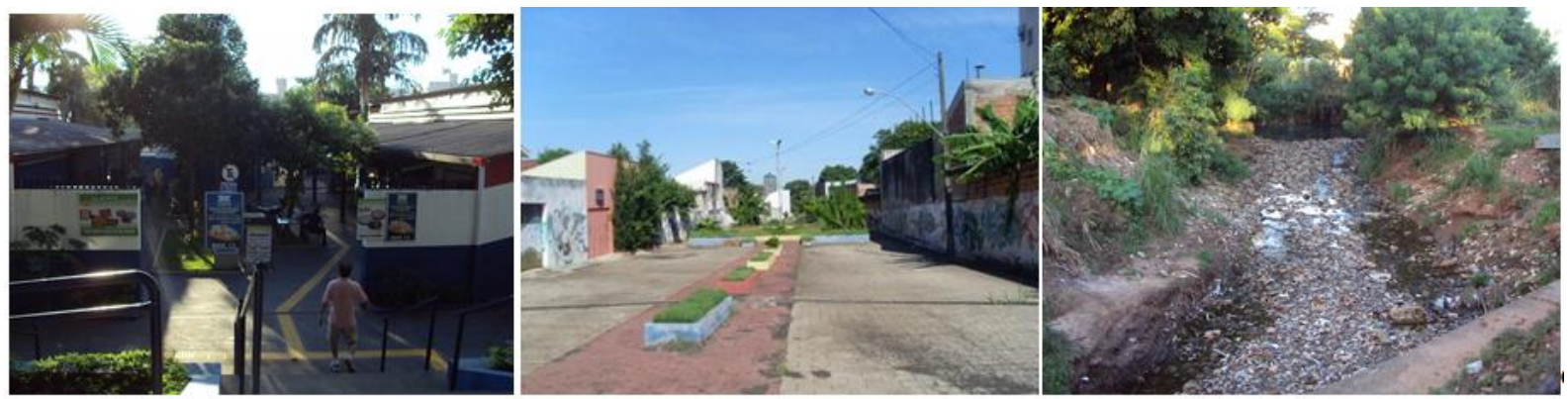

Figura 4. Trechos significantes do Córrego Água Bôscoli: Mercado Modelo, a Área de Lazer, e por último, seu trecho descoberto. Acervo da autora.

Por meio de entrevistas, percebeu-se que a população das áreas adjacentes ao córrego o vê como obstáculo, sendo favorável à sua canalização e tamponamento. Mesmo quando algum entrevistado lamenta essa situação do córrego suprimido pela urbanização, há um clima de conformação, devido à situação de descaso. A população relaciona a figura do córrego à sujeira.

\section{DISCUSSÃO}

Como resposta ao crescimento urbano, que chegava as áreas adjacentes aos córregos, ocorreu a reurbanização dos fundos de vale para atender as necessidades de expansão urbana. Isso aconteceu devido às pressões políticas, e imobiliárias, desconsiderando o planejamento adequado à cidade como um todo. Como características de ocupação das áreas de fundo na cidade, tem-se "a supressão da vegetação e os remanescentes de matas ciliares; carência de áreas verdes e de lazer; a diluição de esgotos; a deposição de resíduos sólidos; a retificação e a canalização dos cursos d'água" (IKUTA, 2003).

É interessante considerar que córregos, rios, ferrovias ou estradas, além de sua implicação física, constituem-se em 'barreiras psicológicas' ao crescimento da cidade, devido à dificuldade que impõem à circulação e acesso (SPOSITO, 1995, p.12). De fato, a barreira espacial que o córrego constituía aos caminhos quando aberto foi muito apontada durante as entrevistas. Nenhum dos loteamentos analisados considera o córrego em seu traçado, pois as quadras e lotes têm os fundos diretamente voltados para corpo d'água: o córrego como fundo de lote.

\section{CONCLUSÃO}

O córrego foi desconsiderado ao longo da ocupação da cidade e sua APP (Área de Preservação Permanente) está totalmente ocupada. A importância dos corpos d'água em área 
urbana é desconsiderada, e na medida em que são esquecidos no processo de ocupação da cidade há desarticulação do espaço urbano. Isso se reflete no próprio traçado dos loteamentos.

Não apenas o poder público tratou o córrego com descaso, optando pela canalização e tamponamento, mas também a população, de modo geral, pelo fato de verem esta como a única solução viável. Este fato demonstra como a cidade não sabe conviver harmonicamente com um córrego em meio urbano.

Esse problema requer que os rios e córregos devam ser tratados como patrimônios ambientais, com a devida consideração a partir da articulação de diversos aspectos: funcional, ambiental e, também, cultural e estético. Este trabalho contribui para a discussão do modelo de ocupação destas áreas de fundo de vale no planejamento das cidades. Adicionalmente, é preciso educar a população para reconhecer a importância do córrego.

\section{REFERÊNCIAS}

DEL RIO, V. Introdução ao desenho urbano no processo de planejamento. São Paulo: Pini, 1990.

FRANCISCO, A. M. Os desafios do planejamento urbano em áreas de fundo de vale consolidadas: o caso da Microbacia do Córrego do Veado em Presidente Prudente, SP. In: Seminário Nacional Sobre o Tratamento de Áreas de Preservação Permanente em Meio Urbano: abordagens, conflitos e perspectivas nas cidades brasileiras - APPURBANA, II, 9 a 11 de maio de 2012, Natal. Anais... Natal: UFRN, 2012.

IKUTA, F. A. A cidade e as águas: expansão territorial urbana e a ocupação dos fundos de vales em Presidente Prudente-SP. 2003. Dissertação (Mestrado em Geografia) - Faculdade de Ciências e Tecnologia, Universidade Estadual Paulista “Júlio de Mesquita Filho", Presidente Prudente, 2003.

LAMAS, J. M. R. G. Morfologia Urbana e Desenho da Cidade. Lisboa: Ed. Fundação Gulbenkian, 1993.

MASCARÓ, J. L. Loteamentos Urbanos. Porto Alegre: L, Mascaró, 2003.

PANERAI, P. Análise urbana. Trad. Francisco Leitão. Brasília: Editora da UNB, 2006.

PEREIRA, S. R. Expansão e Estruturação interna do Espaço Urbano de Presidente Prudente. Formação, vol. 2, No. 13, 226 p., 2006.

SPOSITO, M. E. B. O “chão" em Presidente Prudente: a lógica de expansão territorial urbana. 1983. Dissertação (mestrado) - Instituto de Geociências e Ciências Exatas de Rio Claro, Universidade Estadual Paulista "Júlio de Mesquita Filho", Rio Claro, SP, 1983.

SPOSITO, M. E. B. A Expansão Territorial Urbana de Presidente Prudente.. Recortes, No. 4, 61 p., 1995. 